\title{
A Retrospective Evaluation of the Epithelial Changes/Lesions and Neoplasms of the Gallbladder in Turkey and a Review of the Existing Sampling Methods: A Multicentre Study
}

\author{
Güldal ESENDAĞLI ${ }^{1}$, F. Göknur AKARCA ${ }^{1}$, Serdar BALCI ${ }^{2}$, Asuman ARGON³ ${ }^{3}$, Selma ŞENGiZ ERHAN", \\ Nesrin TURHAN ${ }^{5}$, Neslihan INCE ZENGIN 5 , Sevinç HALLAÇ KESER ${ }^{6}$, Betül ÇELIK ${ }^{7}$, Tangül BULUT7 , \\ Samir ABDULLAZADE ${ }^{8}$, Esra ERDEN ${ }^{9}$, Berna SAVAŞ ${ }^{9}$, Temmuz BOSTAN ${ }^{9}$, Özgül SAĞOL $^{10}$, \\ Anıl AYSAL AĞALAR ${ }^{10}$, Nuray KEPIL ${ }^{11}$, Yıldırım KARSLIOĞLU ${ }^{12}$, Armağan GÜNAL ${ }^{12}$, Fatma MARKOÇ ${ }^{13}$, \\ Burcu SAKA ${ }^{14}$, Gonca ÖZGÜN ${ }^{15}$, Şükrü Oğuz ÖZDAMAR ${ }^{16}$, Burak BAHADIR ${ }^{16}$, Esin KAYMAZ ${ }^{16}$, Emre IŞIK ${ }^{16}$, \\ Semin AYHAN ${ }^{17}$, Deniz TUNÇEL ${ }^{18}$, Banu ÖZGÜVEN YILMAZ ${ }^{18}$, Sevinç ÇELIK ${ }^{19}$, Tuba KARABACAK $^{20}$, \\ İpek ERBARUT SEVEN ${ }^{21}$, Çiğdem ATAizi ÇELIKEL ${ }^{21}$, Zuhal GÜCiN²2, Özgür EKINCí', Gülen AKYOL'1 \\ Department of Medical Pathology, ${ }^{\prime}$ Gazi University School of Medicine, ANKARA, TURKEY, ${ }^{2}$ Ankara University Yıldırım Beyazı School of Medicine, ANKARA, TURKEY \\ Department of Pathology, ${ }^{3}$ Izmir Bozyaka Training and Research Hospital, IZMIR, TURKEY, ${ }^{4}$ Okmeydani Training and Research Hospital, ISTANBUL, TURKEY, \\ ${ }^{5}$ Turkiye Yuksek ihtisas Training and Research Hospital, ANKARA, TURKEY, ${ }^{6}$ Dr. Lutfi Kirdar Training and Research Hospital, ISTANBUL, TURKEY \\ 'Department of Medical Pathology, University of Health Science, Antalya Training and Research Hospital, ANTALYA, TURKEY \\ ${ }^{8}$ Department of Pathology, Izmir Tepecik Training and Research Hospital, IZMIR, TURKEY \\ Department of Medical Pathology, ${ }^{9}$ Ankara University School of Medicine, ANKARA, TURKEY, ${ }^{10}$ Dokuz Eylül University School of Medicine, IZMIR, TURKEY, \\ "Istanbul University, Cerrahpaşa School of Medicine, ISTANBUL, TURKEY \\ Department of Pathology, ${ }^{12}$ Gülhane Training and Research Hospital, ANKARA, TURKEY, ${ }^{13}$ Dr. Abdurrahman Yurtaslan Ankara Onkoloji Training and Research Hospital, \\ ANKARA, TURKEY, ${ }^{14}$ Istanbul University Medipol School of Medicine, ISTANBUL, TURKEY \\ Department of Medical Pathology, ${ }^{15}$ Başkent University School of Medicine, ANKARA, TURKEY, ${ }^{16}$ Bülent Ecevit University School of Medicine, ZONGULDAK, TURKEY, \\ ${ }^{17}$ Celal Bayar University School of Medicine, MANISA, TURKEY \\ ${ }^{18}$ Department of Pathology, Şişli Hamidiye Etfal Training and Research Hospital, ISTANBUL, TURKEY \\ Department of Medical Pathology, ${ }^{19}$ Bozok University School of Medicine, YOZGAT, TURKEY, ${ }^{20}$ Mersin University School of Medicine, MERSIN, TURKEY \\ ${ }^{21}$ Department of Pathology, Marmara University School of Medicine, Pendik Training and Research Hospital, ISTANBUL, TURKEY \\ ${ }^{22}$ Department of Medical Pathology, Bezmialem Foundation University School of Medicine, ISTANBUL, TURKEY
}

\section{ABSTRACT}

Objective: As there is continuing disagreement among the observers on the differential diagnosis between the epithelial changes/lesions and neoplasms of the gallbladder, this multicentre study was planned in order to assess the rate of the epithelial gallbladder lesions in Turkey and to propose microscopy and macroscopy protocols.

Material and Method: With the participation of 22 institutions around Turkey that were included in the Hepato-Pancreato-Biliary Study Group, 89,324 cholecystectomy specimens sampled from 2003 to 2016 were retrospectively evaluated. The numbers of adenocarcinomas, dysplasias, intracholecystic neoplasms/adenomas, intestinal metaplasias and reactive atypia were identified with the review of pathology reports and the regional and countrywide incidence rates were presented in percentages.

Results: Epithelial changes/lesions were reported in $6 \%$ of cholecystectomy materials. Of these epithelial lesions, $7 \%$ were reported as adenocarcinoma, $0.9 \%$ as high-grade dysplasia, $4 \%$ as low-grade dysplasia, $7.8 \%$ as reactive/regenerative atypia, $1.7 \%$ as neoplastic polyp, and $15.6 \%$ as intestinal metaplasia. The remaining lesions (63\%) primarily included non-neoplastic polypoids/hyperplastic lesions and antral/pyloric metaplasia. There were also differences between pathology laboratories.

Conclusion: The major causes of the difference in reporting these epithelial changes/lesions and neoplasms include the differences related to the institute's oncological surgery frequency, sampling protocols, geographical dissimilarities, and differences in the diagnoses/interpretations of the pathologists. It seems that the diagnosis may change if new sections are taken from the specimen when any epithelial abnormality is seen during microscopic examination of the cholecystectomy materials.

Key Words: Gallbladder, Cholecystectomy, Dysplasia, Neoplasia, Sampling

(Turk Patoloji Derg 2018, 34:41-48)

Received : 27.03.2017 Accepted : 25.05.2017
Correspondence: Güldal ESENDAĞLI

University of Gazi School of Medicine,

Department of Medical Pathology, ANKARA, TURKEY

E-mail:drguldal@yahoo.com Phone: +90 3122025488 


\section{INTRODUCTION}

Although resection materials of the gallbladder (cholecystectomy specimens) are common in our daily routine, there are certain problems with the approaches towards the epithelial changes/lesions and the neoplasms of the gallbladder and this issue continues to be relevant with increasing importance. It is a question of debate which lesions are to be reported, in which cases a new sampling would be required and how and by what size the resection would be performed. Besides, there is disagreement among the observers on the differential diagnosis between the epithelial changes in reactive/regenerative atypia or intestinal metaplasia and low-grade dysplasia, and between high-grade dysplasia and invasive tumours. For this very reason, our Hepato-Pancreato-Biliary Study Group (HPBSG) planned a multicentre study in order to assess the rate of the epithelial gallbladder lesions in our country and to propose microscopy and macroscopy protocols and we collected the pathology report diagnoses of gallbladder resection specimens from multiple centres in Turkey.

Epithelial changes/lesions and neoplasms of the gallbladder are rarely encountered lesions $(1,2)$. However, as cholecystectomy is a relatively common surgical procedure, epithelial lesions of the gallbladder, as rare as they are, may be confronted by surgical pathologists. Among the epithelial changes/lesions of the gallbladder, one can count metaplastic changes/lesions (antral/pyloric metaplasia, intestinal metaplasia), benign epithelial neoplasms (adenomas/cystadenomas), biliary intraepithelial neoplasias (BilIN) (dysplasia/carcinoma in situ), and invasive carcinomas (2). The protocols to be followed in sampling and microscopic examination of the gallbladder are still

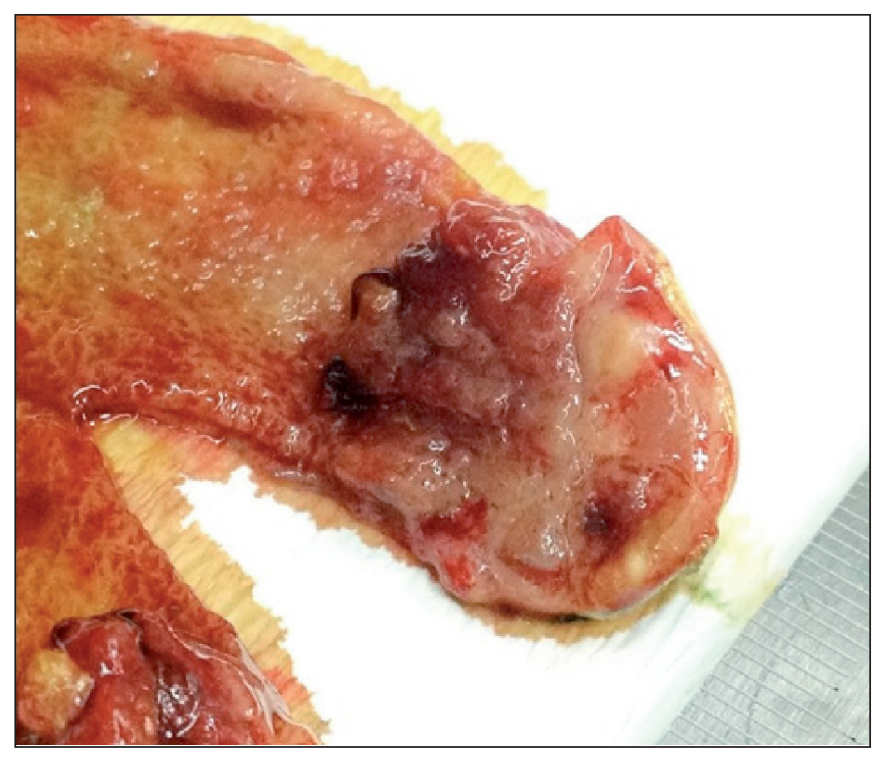

Figure 1: Mass forming invasive adenocarcinoma of gallbladder. of paramount importance and continue to be an issue of debate as high-grade dysplasia and even invasive carcinoma cannot be macroscopically identified to a large extent (3).

\section{MATERIALS and METHOD}

In this multicentre study conducted with the participation of 22 institutions around Turkey that are included in the HPBSG, 89,324 cholecystectomy specimens sampled in various time periods from 2003 to 2016 were retrospectively evaluated. The number of adenocarcinomas (primary invasive carcinomas), low- and high-grade dysplasias such as BilIN, intracholecystic neoplasms/adenomas, intestinal metaplasias, reactive atypia, and some other lesions was identified. As this work, which is the first step of our study, aim to provide awareness of where we stand in terms of gallbladder lesions and cholecystectomy sampling, only the pathology results were evaluated where it was noticed that each institute had their own sampling method which usually includes three tissue samples from the gallbladder wall without any standardized sampling criteria dedicated to this issue. Then, the regional and countrywide incidence rates were presented in percentages.

\section{RESULTS}

In the retrospective review of 89,324 cholecystectomy specimens obtained from all centres that participated in the study, it was found that epithelial changes/lesions were reported in 5,293 of these specimens (6\%). Of those lesions, $411(7 \%)$ were reported as adenocarcinoma (Figure 1,2), $49(0.9 \%)$ as high-grade dysplasia (Figure 3), 208 (4\%) as low-grade dysplasia (Figure 4), $413(7.8 \%)$ as reactive/ regenerative atypia (Figure 5), $90(1.7 \%)$ as neoplastic polyp (biliary adenoma-tubular/tubulopapillary/villous),

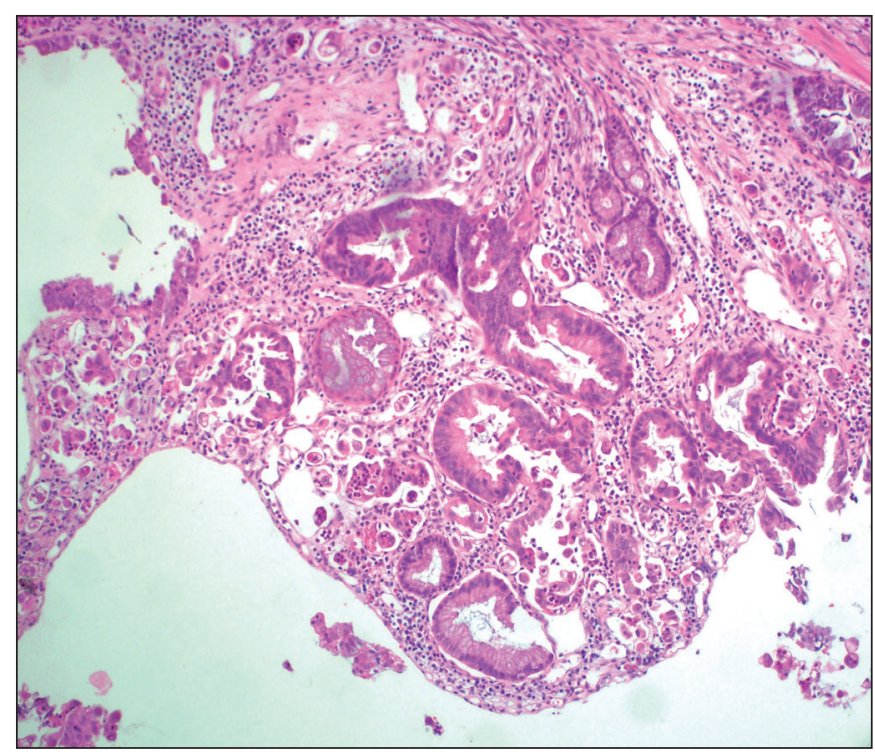

Figure 2: Invasive adenocarcinoma of gallbladder (H\&E; x100). 
and $831(15.6 \%)$ as intestinal metaplasia (Figure 6). The remaining 3,291 lesions (63\%) included primarily nonneoplastic polypoids/hyperplastic lesions and antral/pyloric metaplasias (Figure 7). The differences in the findings of the pathology laboratories showed the rates to be between $0.11 \%-5 \%$ for adenocarcinoma, $0.03 \%-5 \%$ for high-grade dysplasia, \%0.14-\%16 for low-grade dysplasia, $0.12 \%-2.5 \%$ for reactive/regenerative atypia, $0.03 \%-11 \%$ for neoplastic polyp, and $0.05 \%-5 \%$ for intestinal metaplasia (Table I and Figure 8). Besides, in the cholecystectomy specimens with identified intestinal metaplasia, accompanying lesions such as low- and high-grade dysplasias (3.03\%), antral

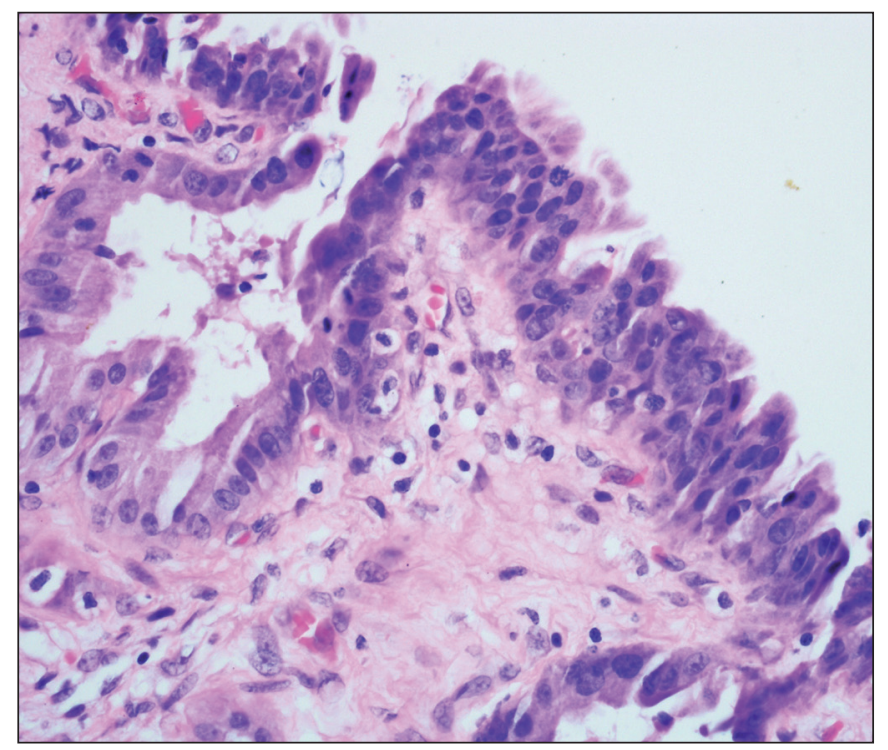

Figure 3: High-grade dysplasia in gallbladder epithelium (H\&E; $\mathrm{x} 400)$.

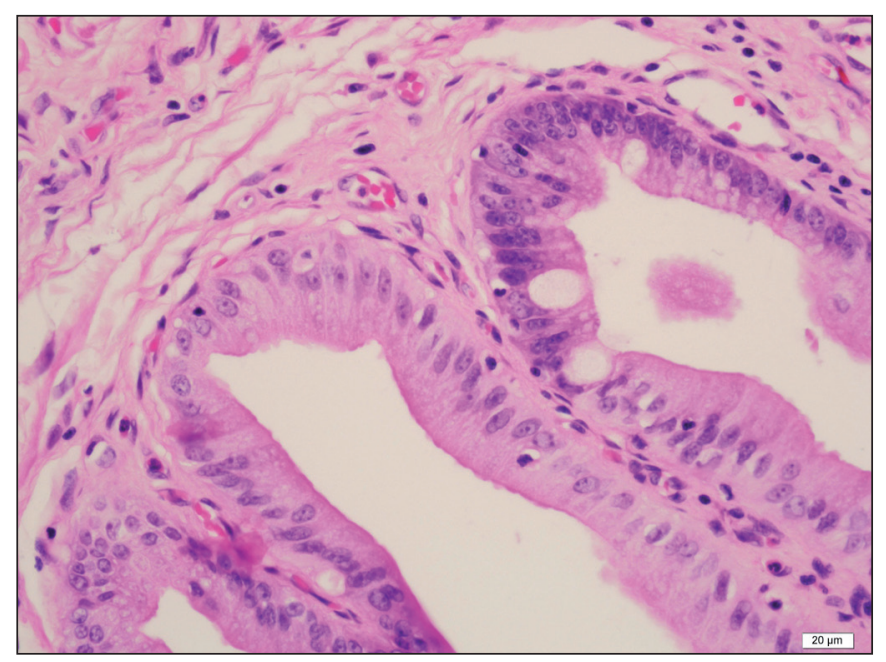

Figure 5: Reactive atypia in gallbladder epithelium nearby intestinal metaplasia (H\&E; $\mathrm{x} 400)$. metaplasia $(2.65 \%)$, adenocarcinoma $(1.1 \%)$ and reactive atypia $(0.12 \%)$ were also found (Table II).

The geographical distribution of certain important lesions is presented in Table III. Because results from the Black Sea Region were obtained from only one centre, specimens from that region are relatively limited in number. According to the available data, the highest rates of invasive adenocarcinoma was found in the Aegean Region while the highest rate of high-grade dysplasia was in yjr Mediterranean Region, the highest rate of reactive atypia and intestinal metaplasia was in the Black Sea Region, and the highest rate of biliary adenoma was in the Central Anatolia Region.

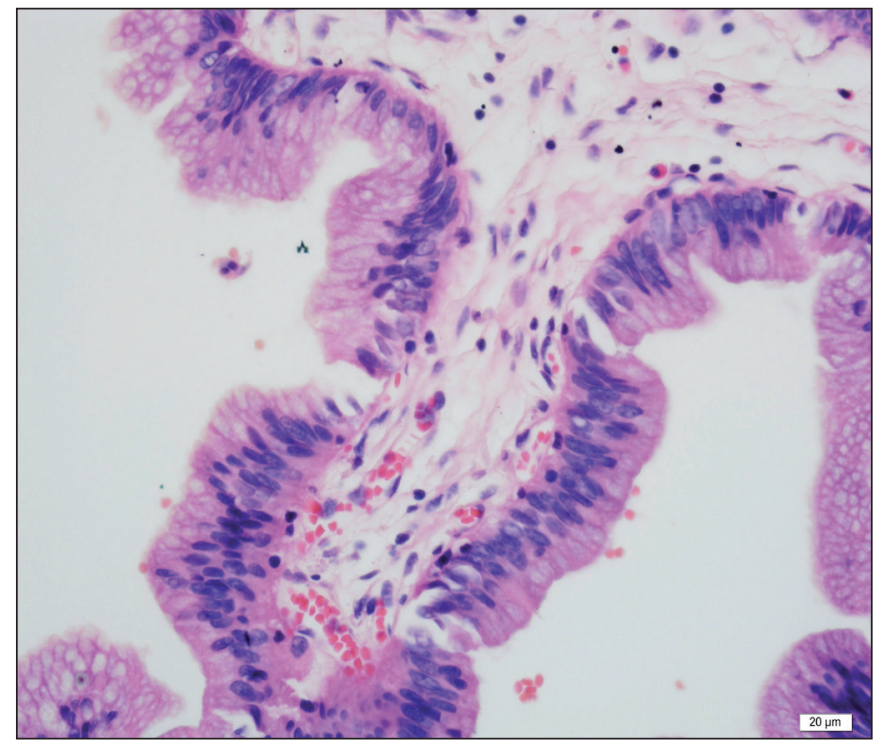

Figure 4: Low-grade dysplasia in gallbladder epithelium (H\&E; $\mathrm{x} 400)$.

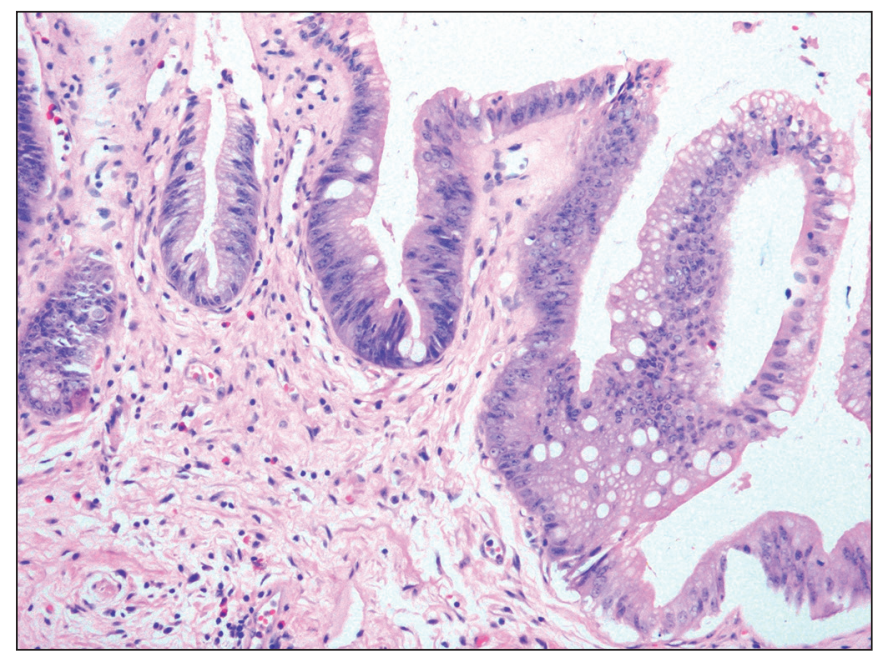

Figure 6: Intestinal metaplasia in gallbladder epithelium (H\&E; $\mathrm{x} 400)$. 


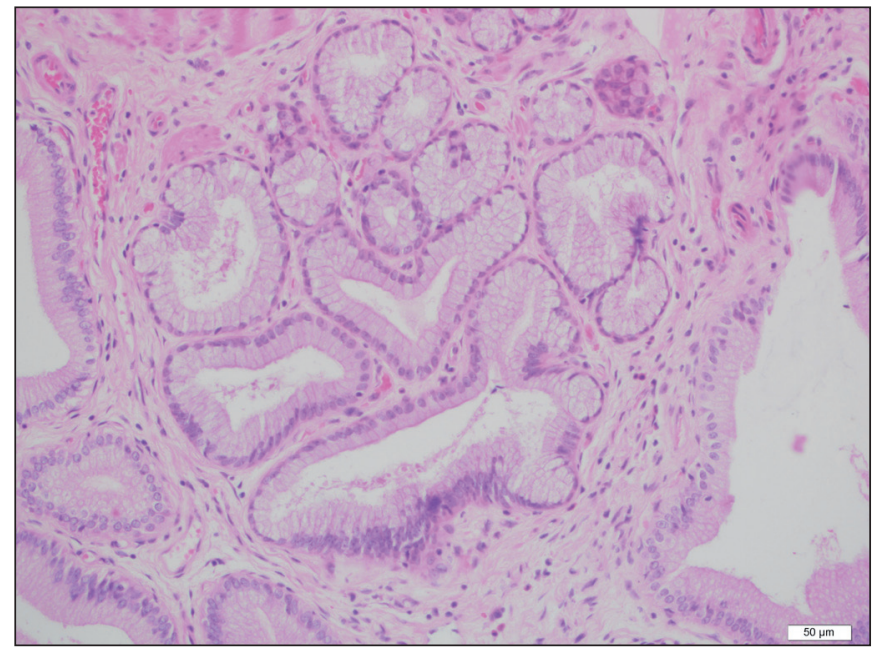

Figure 7: Antral metaplasia in gallbladder epithelium (H\&E; $\mathrm{x} 200)$.

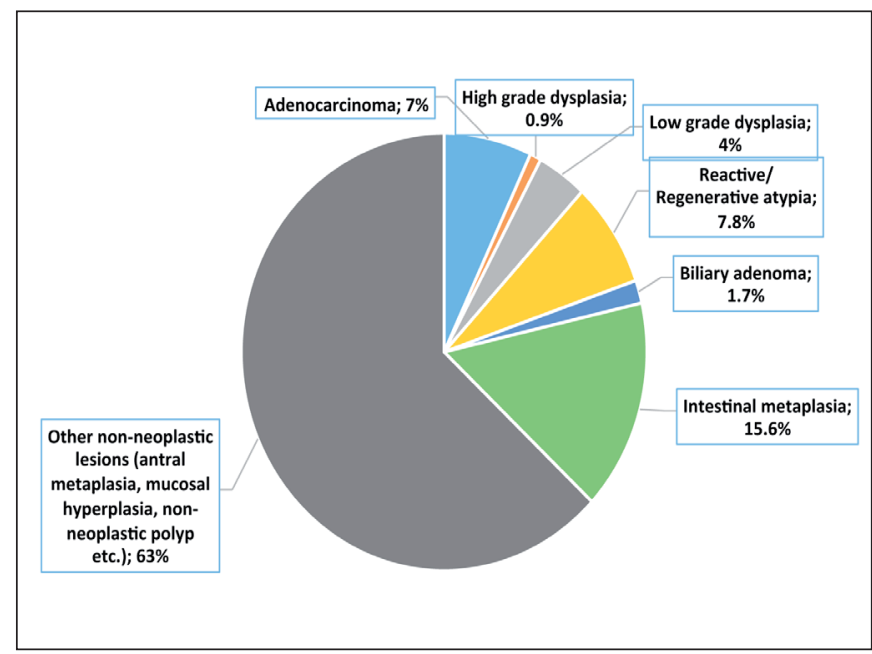

Figure 8: The percentages of epithelial lesions detected in cholecystectomy specimens.

Table I: The percentages of epithelial changes/lesions detected in cholecystectomy specimens

\begin{tabular}{|c|c|c|}
\hline Epithelial lesions of the gallbladder (n: 5,293 ) & In all epithelial lesions & In all cholecystectomy specimens \\
\hline Adenocarcinoma (n:411) & $7 \%$ & $0.4 \%$ \\
\hline High-grade dysplasia (n:49) & $0.9 \%$ & $0.05 \%$ \\
\hline Low-grade dysplasia (n:208) & $4 \%$ & $0.2 \%$ \\
\hline Reactive/Regenerative atypia (n:413) & $7.8 \%$ & $0.4 \%$ \\
\hline Biliary adenoma (n:90) & $1.7 \%$ & $0.1 \%$ \\
\hline Pure intestinal metaplasia $(\mathrm{n}: 831)$ & $15.6 \%$ & $0.9 \%$ \\
\hline $\begin{array}{l}\text { Other non-neoplastic lesions (antral metaplasia, mucosal } \\
\text { hyperplasia, non-neoplastic polyp etc.) (n:3,291) }\end{array}$ & $63 \%$ & $3.79 \%$ \\
\hline
\end{tabular}

Table II: The percentages of accompanying epithelial lesions in the presence of intestinal metaplasia

\begin{tabular}{lccccc}
\hline & Adenocarcinoma & Dysplasia & Biliary adenoma & Reactive atypia & Antral metaplasia \\
\hline Intestinal metaplasia & $1.10 \%$ & $3.03 \%$ & $0.12 \%$ & $0.12 \%$ & $2.65 \%$ \\
\hline
\end{tabular}

Table III: Distribution of certain major epithelial lesions by geographical regions

\begin{tabular}{lccccc}
\hline & $\begin{array}{c}\text { Marmara } \\
\text { Region }\end{array}$ & $\begin{array}{c}\text { Aegean } \\
\text { Region }\end{array}$ & $\begin{array}{c}\text { Central Anatolia } \\
\text { Region }\end{array}$ & $\begin{array}{c}\text { Mediterranean } \\
\text { Region }\end{array}$ & $\begin{array}{c}\text { Black Sea } \\
\text { Region }\end{array}$ \\
\hline Adenocarcinoma & $87(0.37 \%)$ & $191(0.80 \%)$ & $85(0.29 \%)$ & $45(0.57 \%)$ & $3(0.4 \%)$ \\
\hline High-grade dysplasia & $16(0.07 \%)$ & $8(0.03 \%)$ & $15(0.05 \%)$ & $10(0.13 \%)$ & 0 \\
\hline Low-grade dysplasia & $104(0.44 \%)$ & $91(0.38 \%)$ & $98(0.33 \%)$ & $50(0.64 \%)$ & $16(2.2 \%)$ \\
\hline Reactive atypia & $49(0.21 \%)$ & $3(0.01 \%)$ & $293(0.99 \%)$ & $42(0.54 \%)$ & $26(3.6 \%)$ \\
\hline Biliary adenoma & $21(0.09 \%)$ & $13(0.06 \%)$ & $48(0.16 \%)$ & $8(0.10 \%)$ & 0 \\
\hline Intestinal metaplasia & $294(1.26 \%)$ & $205(0.86 \%)$ & $226(0.76 \%)$ & $67(0.86 \%)$ & $39(5.4 \%)$ \\
\hline Total cholecystectomy materials & 23,426 & 23,840 & 29,862 & 7,840 & 714 \\
\hline
\end{tabular}

\section{DISCUSSION}

Various epithelial changes/lesions developing from the gallbladder mucosa are found in cholecystectomy specimens. The spectrum of these epithelial changes/lesions primarily included metaplastic changes, benign neoplasms (adenomas), low- and high-grade dysplasias as BilIN and invasive adenocarcinomas. 
Gallbladder carcinomas are usually incidentally detected in cholecystectomy specimens taken out due to cholestasis and display themselves as carcinoma in situ or carcinoma with superficial invasion (2). In our study, the rate of primary invasive adenocarcinoma in all cholecystectomy specimens was found to be $0.4 \%$ and this rate is reported in the literature to be between $0.15-2.3 \%$ (4-10). In addition, the world-wide incidence, mortality, and prevalence rate for 5 years of gallbladder cancer is reported, respectively, to be $1.3 \%, 1.7 \%$, and $06 \%$ in the GLOBOCAN Project that establishes up-to-date estimates at the national level about the incidence, mortality, and prevalence for major cancers in many countries (11). In our study, the prevalence rate for 5 years for gallbladder cancer was found to be $0.5 \%$ for Turkey and this figure is in accordance with the data provided by GLOBOCAN.

Gallbladder dysplasia is not a frequent condition and its incidence is reported to be $3.3 \%$ (12). However, there are studies in the literature that claim this rate can go up to $25 \%$ (13-16). The rate of dysplasia detected in all cholecystectomy specimens in our study, on the other hand, was $0.25 \%$. The number of studies in the literature that focuses on this issue is not adequate but the rate is reported to be between $0.7-3.3 \%$ in all studies available $(5-7,12)$. The fact that the rate found in our study is well below the ones reported in the literature suggests that either these pre-neoplastic epithelial lesions could not be sampled or not recognized enough or low-grade dysplasia was misinterpreted as regenerative atypia. It is reported in different series that the incidence rate of intestinal metaplasia is $10-30 \%$ among all cholecystectomy specimens (2). A striking result in this respect was found in a study conducted in the population of Chile, which is known to have a relatively higher rate of gallbladder cancer. The rate of intestinal metaplasia detected in cholecystectomy specimens was reported in this study to be $58.1 \%$ (17). In our study, the relevant result was $0.9 \%$. This figure was again below the ones reported in the literature and it was thought that this results from the discrepancies in routine reporting of intestinal metaplasia in pathology reports by pathologists and/or institutions and the non-uniformity in macroscopic sampling.

For macroscopic examination and sampling of cholecystectomy specimens, it was recommended in the handbook of macroscopic examination (18) prepared by the HPBSG of the Federation of Turkish Pathology Societies in 2013 that all cholecystectomy specimens should be handled according to the following: (i) The specimen should be measured in three dimensions, opened on the anti-hepatic side and the bile drained off. It should be noted whether the gallbladder has already been opened and the container in which the specimen has been sent should be investigated for lesions that may have come off. The specimen should not be opened in the sink under running water. (ii) The number, size, shape and colour of the gallstones should be described. (iii) The mucosa should be examined thoroughly and its appearance, yellow mottlings, and whether it has an ulcer or a mass lesion be specified. (iv) The thickness of the gallbladder wall should be documented based on the thickest part of the specimen. (v) The neck (isthmic) lymph node (so called "Cattle ganglion") should meticulously be searched for and sampled completely after being cut into two. (iv) The surgical margin of the cystic duct and the hepatic aspect of the gallbladder should be marked with ink and the samples from the peritonealized surface of the organ should be noted, and also painted with ink. This handbook also includes recommendations on the sampling method and the number of slices to be sampled in cholecystectomies performed due to tumour-associated or non-tumour-associated reasons or due to the existence of tumour suspicion on macroscopic examination.

It is also noticed that various sampling methods are available for the sampling of cholecystectomy specimens in the reference books of pathology that are in current international use. Among these are: (i) especially for the specimens with a prediagnosis of carcinoma, draining off the bile with the help of an injector, injecting formalin in the bladder, leaving the specimen to be fixed in formalin overnight and then opening and sampling; for other specimens, sampling three pieces each from the fundus, body, and the neck to represent the whole wall of the gallbladder and sampling cystic duct and any lymph node in case of any macroscopic abnormality (19); (ii) sampling by multiple transverse sections after rolling the emptied organ to examine the whole mucosa on a single slide, especially for the specimens with suspicion of carcinoma in situ or dysplasia (12); (iii) sampling by circumferential transverse sectioning of the proximal cystic duct margin and by one slice divided into appropriate pieces obtained from a whole cut transverse section of the cholecystectomy specimens without any macroscopic abnormality (20); (iv) sampling of the fundus and neck of the gallbladder each cut in the transverse plane and the margin of cystic duct with fine transverse sectioning (21).

There are also several studies in our country on the prevalence of epithelial lesions in the gallbladder mucosa. As for dysplasia and intestinal metaplasia which are thought to have a connection with the development of adenocarcinoma and neoplasms, Bahadir et al. (22) detected 
intestinal metaplasia in 24 of the 351 gallbladders with 11 having epithelial dysplasia of varying degrees. Incidental carcinoma was found in 4 of the 11 cases with intestinal metaplasia and dysplasia. In their study on polypoid lesions, Ylldirim et al. (23) detected 1 case of adenocarcinoma in 1420 cholecystectomy specimens. In a similar study by Tunçel et al. (24), 1 adenocarcinoma was reported in 99 polypoid lesions that were found in 4,479 cholecystectomy specimens. Koca et al. (25) reported the incidence of carcinoma, biliary intraepithelial neoplasia and papillary neoplasia as approximately $2 \%$. A similar percentage was also reported by Mazlum et al. (26). Argon et al. (27) recommend sampling a full slice longitudinally all along the gallbladder as this method reveals the presence of a higher number of pyloric metaplasia, intestinal metaplasia, lowgrade dysplasia, and invasive carcinoma than the method of sampling the fundus and the body separately. Bolat et al. (28) stated that the routine method in their pathology laboratory is to take three samples from cholecystectomy specimens. They mapped and examined 75 cholecystectomy specimens and reported that they observed an increase in the incidence of metaplasia, dysplasia, and early carcinoma detection when the number of samplings was increased.

The adenoma-carcinoma sequence has also been extensively debated recently (2). Some authors claim that the adenomacarcinoma sequence is a natural process in adenocarcinoma development (29). There are other studies that support this idea, stating that there is a presence of adenomatous residue in the areas where invasive carcinoma develops (30). There are also other publications of case series where early microcarcinoma development in the area of adenoma was reported (31) and there are also certain studies that focus on the adenomas with dysplasia-carcinoma in situinvasive carcinoma development including pyloric gland adenomas (32). However, the results obtained from a comprehensive series study do not support this view (2). Intestinal metaplasia has been reported to have a significant correlation with epithelial hyperplasia and dysplasia (17).

The importance and necessity of specifying each and every lesion encountered in the gallbladder is also another object at issue. It seems that the diagnosis may change if new sections are taken from the specimen when any epithelial abnormality is seen during microscopic examination of the cholecystectomy materials (3). Bivins et al. (33) assert that 4 sections would be sufficient in detecting most cases of dysplasia. Similarly, it is reported that, in cases where dysplasia or reactive atypia is detected after the routine sampling process, a re-sampling of up to 4 sections cut from the re-examined gallbladder is sufficient in detecting all important lesions and that sampling the entire gallbladder is not necessary (34). In cases of in situ carcinoma/highgrade dysplasia where the suspicion of invasion is excluded and the given lesions are entirely followed up, the clinical course has been reported to be quite good $(35,36)$. However, criteria for both sampling and diagnosis of low-grade lesions and for the differentiation between reactive atypia and low-grade dysplasia have not been clearly specified yet (37). Pathologists generally feel the need for sampling new sections and extending the investigation mostly when highand low-grade BilIN is present. According to Renshaw and Gould (34), consultant institutions recommend a reexamination of the cholecystectomy specimen and sampling of the entire gallbladder upon identification of these lesions but this, in accordance with the aforementioned study, is not a necessary and appropriate approach in order to reach a definitive diagnosis. Regarding the stance of these authors, in a short article written by Adsay et al. (3) in 2013, it is stated that neoplastic lesions are not easily identified, particularly in macroscopic examination of the gallbladder samples, and the risk in the population should also be taken into account in these terms. It is also emphasized that the relative coexistence of epithelial lesions in the gallbladder with neoplastic lesions should be kept in mind. Regarding this issue, the decision taken in the consensus meeting sponsored by Americas Hepato-Pancreato-Biliary Association in 2015 asserts that in high incidence areas, sampling of the routine cholecystectomy specimens should include a minimum of three sections representing the wall of the bladder and the cystic duct margin; and that the specimens with dysplasia or cancer should be entirely sampled (38).

As proven above, there are various methods and recommendations in the literature and reference books for surgical pathology regarding the procedure for the sampling of cholecystectomy specimens.

In conclusion, although the percentage of invasive carcinoma in all cholecystectomy specimens examined in our study is compatible with the ones in the literature, the rates of metaplasias and neoplasms are different and also the incidence rate of the lesions differ from one institution to another. The major causes of this difference include the differencesin the frequency of oncological surgeryamong the institutions, non-uniformity of the macroscopic sampling protocols, geographical dissimilarities, and the differences in the diagnoses/interpretations of the pathologists. Besides, during the routine pathology practices, pathologists do not feel the need for reporting some epithelial changes/lesions identified in the cholecystectomy specimens (i.e. antral and intestinal metaplasia). 
It is necessary for putting an end to this confusion to identify the accurate incidence rate of the gallbladder lesions in Turkey, design a common path for the standardisation of reporting with uniformity in diagnosis/terminology and to conduct more studies including different geographical regions by developing a new standardised method of macroscopic sampling and microscopic examination. In accordance with the results obtained, new sampling criteria were specified and a prospective multicentre study has been commenced with the aim of identifying the accurate incidence rate of gallbladder lesions, standardising the reporting process, and promoting uniformity in the diagnosis/terminology according to these prescribed methods of macroscopic sampling and microscopic examination.

\section{CONFLICT of INTEREST}

The authors declare no conflict of interest.

\section{REFERENCES}

1. Adsay NV. Gallbladder, extrahepatic biliary tree, and ampulla, in Sternberg's diagnostic surgical pathology, Mills SE, editor. Philadelphia: Wolters Kluwer; 2015:1770.

2. Albores-Saavedra J, Henson DE, Klimstra DS. Benign epithelial tumors of the gallbladder. In: AFIP atlas of tumor pathology. Fourth series. In: Tumors of the gallbladder, extrahepatic bile ducts, and vaterian system. Maryland: ARP Silver Spring;2015:31-50.

3. Adsay V, Saka B, Basturk O, Roa JC. Criteria for pathologic sampling of gallbladder specimens. Am J Clin Pathol 2013;140:278-80.

4. Utsumi M, Aoki H, Kunitomo T, Mushiake Y, Yasuhara I, Arata T, Katsuda K, Tanakaya K, Takeuchi H. Evaluation of surgical treatment for incidental gallbladder carcinoma diagnosed during or after laparoscopic cholecystectomy: Single center results. BMC Res Notes. 2017;10:56.

5. Patel K, Dajani K, Iype S, Chatzizacharias NA, Vickramarajah S, Singh P, Davies S, Brais R, Liau SS, Harper S, Jah A, Praseedom RK, Huguet EL. Incidental non-benign gallbladder histopathology after cholecystectomy in an United Kingdom population: Need for routine histological analysis? World J Gastrointest Surg. 2016;8:685-92.

6. Wrenn SM, Callas PW, Abu-Jaish W. Histopathological examination of specimen following cholecystectomy: Are we accepting resect and discard? Surg Endosc. 2017;31:586-93.

7. Yamamoto H, Hayakawa N, Kitagawa Y, Katohno Y, Sasaya T, Takara D, Nagino M, Nimura Y. Unsuspected gallbladder carcinoma after laparoscopic cholecystectomy. J Hepatobiliary Pancreat Surg. 2005;12:391-8.

8. Tantia O, Jain M, Khanna S, Sen B. Incidental carcinoma gall bladder during laparoscopic cholecystectomy for symptomatic gall stone disease. Surg Endosc. 2009;23:2041-6.

9. Talreja V, Ali A, Khawaja R, Rani K, Samnani SS, Farid FN. Surgically resected gall bladder: Is histopathology needed for all? Surg Res Pract. 2016;2016:9319147.
10. Raziel A, Sakran N, Szold A, Sandbank J, Hershko D, Goitein D. Adenocarcinoma of the gallbladder: Incidental finding in patients following laparoscopic sleeve gastrectomy and cholecystectomy. Isr Med Assoc J. 2015;17:703-6.

11. Ferlay J, Soerjomataram I, Dikshit R, Eser S, Mathers C, Rebelo M, Parkin DM, Forman D, Bray F. Cancer incidence and mortality worldwide: Sources, methods and major patterns in GLOBOCAN 2012. Int J Cancer. 2015;136:E359-86.

12. Albores-Saavedra J, Henson DE, Klimstra DS. Tumors of the gallbladder, extrahepatic bile ducts, and ampulla of Vater. Atlas of tumor pathology. Third series, fascicle 27. Washington DC: Armed Forces Institute of Pathology;2000

13. Ojeda VJ, Shilkin KB, Walters MN. Premalignant epithelial lesions of the gall bladder: A prospective study of 120 cholecystectomy specimens. Pathology. 1985;17:451-4

14. Albores-Saavedra J, Alcántra-Vazquez A, Cruz-Ortiz H, HerreraGoepfert R. The precursor lesions of invasive gallbladder carcinoma. Hyperplasia, atypical hyperplasia and carcinoma in situ. Cancer. 1980;45:919-27.

15. Sasatomi E, Tokunaga O, Miyazaki K. Precancerous conditions of gallbladder carcinoma: Overview of histopathologic characteristics and molecular genetic findings. J Hepatobiliary Pancreat Surg. 2000;7:556-67.

16. Yamagiwa H. Mucosal dysplasia of gallbladder: Isolated and adjacent lesions to carcinoma. Jpn J Cancer Res. 1989;80:238-43.

17. Duarte I, Llanos O, Domke H, Harz C, Valdivieso V. Metaplasia and precursor lesions of gallbladder carcinoma. Frequency, distribution, and probability of detection in routine histologic samples. Cancer. 1993;72:1878-84.

18. Patoloji Dernekleri Federasyonu, Hepato-Pankreato-Biliyer Patoloji Çalışma Grubu; Yılmaz F, Dursun N, Bağcı P, Balcı S, Deniz K, Sağol Ö, Özdamar Ş, Karslığlu Y. Safra Kesesi ve Safra Yolları Rezeksiyon Materyallerinde Makroskopik Değerlendirme Kilavuzu. http://www.turkpath.org.tr/includes/spaw2/uploads/ files/Hepatobiliyer.pdf, 2013.

19. Rosai J. Appendix E: Guidelines for handling of most common and important surgical specimens. In: Rosai and Ackerman's surgical pathology, Vol:2, 10th ed. St Louis: Elsevier;2011.2601.

20. Allen DC, Cameron IA, Loughrey MB. Gallbladder. In: Histopathology specimens. Clinical, pathological and laboratory aspects. Allen DC and Cameron IA, editors. 2nd ed. London: Springer; 2013.95

21. Abraham S. Gallbladder and extrahepatic biliary system. In: Surgical pathology dissection. An illustrated guide. Westra $\mathrm{WH}$, Hruban RH, Phelps TH, Isacson C, editors. 2nd ed. New York: Springer; 2002. 82-83

22. Bahadır B, Doğan Gün B, Çolak S, Kertiş G, Cömert M, Özdamar ŞO. Safra kesesinde metaplazi, displazi ve karsinom dizgesi. Akademik Gastroenteroloji Dergisi. 2007;6:25-9.

23. Yıldırım M, Erkan N, Yakan S, Boz A, Vardar E. Safra Kesesi polipleri: 33 olgunun retrospektif analizi. ADÜ Tip Fakültesi Dergisi. 2005;6:27-30

24. Tunçel D, Yılmaz Özgüven B, Sarı AG, Kabukçuoğlu F, Özağarı AA, Aksu N, Battal M. Safra kesesinin polipoid lezyonları: 99 olgunun retrospektif analizi. Cukurova Medical Journal. 2015;40:452-6. 
25. Koca SB, Dursun N, Gücin Z, Bağc1 P, Sığırcı BB, Bozkurt ER Kolesistektomi materyalinde neoplazi insidansı ve neoplazilerin histolojik alt tiplendirmeleri. Sözlü Sunum -15 . 21. Ulusal Patoloji Kongresi, 16-20 Kasım 2011, İzmir.

26. Mazlum M, Dilek FH, Yener AN, Tokyol C, Aktepe F, Dilek ON. Profile of gallbladder diseases diagnosed at Afyon Kocatepe University: A retrospective study. Turk Patoloji Derg. 2011;27:2330.

27. Argon A, Yağcı A, Taşlı F, Kebat T, Deniz S, Ersöz D, Erkan N, Kitapçıŏlu G, Vardar E. Kolesistektomi materyallerinin makroskobik örneklemesine farklı bir bakıș. 22. Ulusal Patoloji Kongresi. Sözlü bildiri özetleri (S-012). www.turkpath.org.tr/ UlusalPatoloji2012/?page=sozlu_bildiri_ozetleri

28. Bolat F, Kayaselçuk F, Nursal TZ, Bal N, Tuncer İ. Kolesistektomilerde örnek sayısının artırılması ile histopatolojik bulguların korelasyonu. Türk Patoloji Dergisi. 2007;23:137-42.

29. Albores-Saavedra J, Vardaman CJ, Vuitch F. Non-neoplastic polypoid lesions and adenomas of the gallbladder. Pathol Ann. 1993;28:145-77.

30. Kozuka S, Tsubone N, Yasui A, Hachisuka K. Relation of adenoma to carcinoma in the gallbladder. Cancer. 1982;50:2226-34.

31. Kijima H, Watanabe H, Iwafuchi M, Ishihara N. Histogenesis of gallbladder carcinoma from investigation of early carcinoma and microcarcinoma. Acta Pathol Jpn. 1989;39:235-44.

32. Albores-Saavedra J, Chable-Montero F, Angeles-Albores D, Schwartz A, Klimstra DS, Henson DE. Early gallbladder carcinoma: A clinicopathologic study of 13 cases of intramucosal carcinoma. Am J Clin Pathol. 2011;135:637-42.
33. Bivins BA, Meeker WR Jr, Weiss DL, Griffen WO Jr. Carcinoma in situ of the gallbladder: A dilemma. South Med J. 1975;68:297-300.

34. Renshaw AA, Gould EW. Submitting the entire gallbladder in cases of dysplasia is not justified. Am J Clin Pathol. 2012;138:3746.

35. Dursun N, Saka B, Balci S, Bagci P, Roa JC, Araya JC, Basturk O, Terry P, Minhas F, Ducato L, Adsay V. Biologic behavior of gallbladder high-grade dysplasia: A long-term survival analysis of 125 cases elucidates a mostly curable disease, which is a marker of biliary tract cancer risk in some patients (Abstract). Mod Pathol. 2014;27:173A-A.

36. Patel K, Balci S, Saka B, Knight J, Basturk O, Sarmiento J, Roa JC, Araya JC, Sweeney J, Terry P, Goodman M, Adsay V. "Carcinoma in-situ" of the gallbladder: The SEER database perspective (Abstract). Mod Pathol. 2014;27:452A,3A.

37. Adsay V, Roa JC, Basturk O, Torres J, Mucientes F, Del Pozo M, Villaseca MA, Aguayo G, Bellolio ER, Araya JC, Endo B, Lee K, Jang KT, Jang JY, Ohike N, Shimizu M, Hirabayashi K, Terris B, Zamboni G, Reid M, Xue Y, Bedolla G, Quigley B, Krasinskas A, Akkas G, Memis B, Klimstra D, Hruban RH, Zhu B, Van Dyke AL, Koshiol J. Epithelial atypia in the gallbladder: Diagnosis and classification in an international consensus study (Abstract). Mod Pathol. 2016;29:438A,9A.

38. Aloia TA, Járufe N, Javle M, Maithel SK, Roa JC, Adsay V, Coimbra FJ, Jarnagin WR. Gallbladder cancer: Expert consensus statement. HPB (Oxford). 2015;17:681-90.

39. Hartman D, Krasinskas AM, Sasatomi E. Caveat emptor: Submitting the entire gallbladder in cases of dysplasia is not justified. Am J Clin Pathol. 2013;139:830. 